\title{
MATERIALISMO DIALÉTICO E O ESTUDO DO PROCESSO COMUNICACIONAL DE AD- MINISTRAÇÕES PÚBLICAS MUNICIPAIS
}

TAMARA AREND DE FREITAS

UNIVERSIDADE DE SANTA CRUZ DO SUL SANTA CRUZ DO SUL, RIO GRANDE DO SUL, BRASIL TAMARAARENDF@GMAIL.COM

GRAZIELLE BETINA BRANDT UNIVERSIDADE DE SANTA CRUZ DO SUL (UNISC) SANTA CRUZ DO SUL, RIO GRANDE DO SUL, BRASIL GRAZIELLE@UNISC.BR 


\section{MATERIALISMO DIALÉTICO E O ESTUDO DO PROCESSO COMUNI- CACIONAL DE ADMINISTRAÇÕES PÚBLICAS MUNICIPAIS}

Resumo: Este artigo busca elucidar a utilização do materialismo dialético no estudo do processo comunicacional de administrações públicas municipais, através do estudo do processo comunicacional de três municípios do COREDE do Vale do Rio Pardo (RS). No mesmo, foi possível identificar contradições na dialética intuito/prática dos processos comunicacionais, com semelhanças nos discursos e distinções nas ações.

Palavras-chave: Materialismo dialético; Comunicação; Processo comunicacional; Administração Pública Municipal.

\section{MATERIALISMO DIALÉCTICO Y EL ESTUDIO DEL PROCEDIMIENTO COMUNICACIONAL DE ADMINISTRACIONES PÚBLICAS MUNICIPA- LES}

Resumen: Este artículo busca elucidar la utilización del materialismo dialéctico en el estudio del proceso comunicacional de administraciones públicas municipales, a través del estudio del proceso comunicacional de tres municipios del COREDE do Vale do Rio Pardo (RS). En el mismo, fue posible identificar contradicciones en la dialéctica intuitiva/práctica de los procesos comunicacionales, con semejanzas en los discursos y distinciones en las acciones. Palabras clave: Materialismo dialéctico; Comunicación; Proceso de comunicación; Administración Pública Municipal.

\section{DIALECTICAL MATERIALISM AND THE STUDY OF THE COMMUNICA- TION PROCESS OF MUNICIPAL PUBLIC ADMINISTRATIONS}

Abstract: This article seeks to elucidate the use of dialectic materialism in the study of the communicational process of municipal public administrations, through the study of the communication process of three municipalities of COREDE do Vale do Rio Pardo (RS). In the same, it was possible to identify contradictions in the intuitive/practical dialectic of the communicational processes, with similarities in the discourses and distinctions in the actions. Keywords: Dialectical materialism; Communication; Communication process; Municipal Public Administration.

\section{INTRODUÇÃO}

A principal forma de relação entre o homem e a natureza/meio se dá através da técnica, que se apresenta enquanto "conjunto de meios instrumentais e sociais, com os quais o homem realiza sua vida, produz e, ao mesmo tempo, cria espaço" (SANTOS, 2006, p. 16). Essas técnicas estão relacio- 
nadas com as características da sociedade e do espaço geográfico ao longo de sua evolução, de modo que constituem um elemento de explicação das sociedades e de seus territórios, embora, por si só, não seja suficiente (SANTOS, 1997, 2006). As técnicas são um meio para se alcançar determinado objetivo, sendo o sentido do seu uso dado pelas relações sociais nas quais estão inseridas, ou seja, pelas pessoas envolvidas no processo e seus interesses. Segundo Santos (1997, 2006), cada técnica pode ser localizada no tempo, sendo o tempo do lugar marcado, não apenas por uma técnica de forma isolada, mas por um conjunto de técnicas existentes naquele espaço. Assim, é possível identificar três grandes períodos da história do meio geográfico: o meio natural, o meio técnico e o meio técnico-científico-informacional.

Neste século XXI, a sociedade vive o período que Santos chamou de meio técnico-científico-informacional. $\mathrm{O}$ que o difere dos demais períodos é o fato de a informação ser um fator extremamente importante na forma como os territórios são constituídos e utilizados. Neste período, a globalização se expande , tanto através da ciência quanto da técnica e, principalmente, da informação, tornando mercados, territórios e culturas globais, e estando voltada, em grande parte, aos interesses hegemônicos da economia e da sociedade. A desigualdade já existente agora passa, também, a ser medida pela presença, ou pela escassez, dos novos fatores-chave, uma vez que a ciência, a tecnologia e a informação são as bases técnicas da vida social contemporânea. Contudo, a presença deste meio não se dá em todos os lugares de forma igualitária e, uma vez que os territórios passaram a exigir volumosas parcelas de informação, esta se apresenta como fator de agravamento de diferenças entre regiões, com grande concentração de informações em um limitado número de territórios (SANTOS, 1997, 2006; SANTOS, SILVEIRA, 2006).

A informação - assim como a ciência e a técnica - irá influenciar no processo de desenvolvimento de uma região, sendo o seu conhecimento extremamente importante. Por mais que as técnicas presentes no meio atual estejam, em grande parte, vinculadas aos interesses hegemônicos - influenciando, assim, o acesso às informações -, à práticas perversas, esta perversidade está vinculada ao seu uso, não às técnicas em si. Desse modo, estas mesmas técnicas, se colocadas a serviço de outros fundamentos, tanto sociais quanto políticos, podem ser utilizadas para outros fins, possibilitando se falar em um outro desenvolvimento, distinto do formato atual, que está 
voltado para a competitividade, para o consumo, para uma evolução negativa da sociedade (SANTOS, 2000).

O ideal de um outro desenvolvimento está relacionado à capacidade de participação da sociedade nas ações de órgãos públicos, tendo em vista um crescimento voltado para a satisfação de suas necessidades e expansão de suas liberdades, ou seja , a melhora da qualidade de vida dos cidadãos. Trata-se de um processo endógeno, autônomo e democrático, que permite aos cidadãos exercerem sua cidadania plena ao, não apenas decidir quais serão seus representantes, mas também participar das decisões, fiscalizar e exigir ações de entes públicos. Aqui, a comunicação se faz presente, enquanto meio para favorecer a participação da sociedade, contribuindo para a auto-emancipação cidadã e ampliação da cidadania (SERVAES, 2000; SEN, 2000).

A comunicação para o desenvolvimento tem como função central promover o acesso à informação e reforçar a participação, apresentando-se como ferramenta para a transformação social e política, promovendo a participação e a mudança social através de métodos e instrumentos da comunicação interpessoal, dos meios comunitários e das tecnologias da informação. Nesse sentido, a comunicação para o desenvolvimento tem como intuito facilitar e garantir o acesso à informação, promover a participação e o empoderamento cidadão, bem como influenciar políticas públicas. $O$ processo comunicacional dentro desta perspectiva se realiza de forma horizontal, bi/multidirecional, com foco em processos, transmitindo informação com emoção e mensagens para todos os sentidos. Trata-se, portanto, de uma forma de comunicação baseada no diálogo, no apoio à mudança social e no respeito à cultura local (JENATSCH, BAUER, 2016).

Há que se considerar, entretanto, as diversas dificuldades para a realização de um processo comunicacional com tais características, indo desde barreiras impostas pelo funcionamento tradicional da administração pública, como - burocracia, falta de vontade em criar meios participativos, etc., - até barreiras oriundas das práticas dos cidadãos - desconhecimento/dificuldade no acesso e absorção das informações, falta de vontade em participar, descrença em atividades políticas, etc. (BANDEIRA, 2000; SANT'ANA, 2009). Contudo, tais dificuldades não significam uma impossibilidade de realização. A comunicação, nessa perspectiva, poderá auxiliar na realização desse processo, sendo vista não como uma prática manipuladora e perversa, mas sim "considerada um direito sem o qual outros direitos estariam ameaçados: civis, difusos, humanos, políticos e sociais” (SILVA, 2011, p. 103). 
Portanto, ao falar em uma comunicação voltada para a cidadania e para um outro desenvolvimento, se está falando de um processo de lutas, de conquistas, envolvendo a sociedade e o poder público em busca de um mesmo objetivo. Este processo, por sua vez, não ocorre de forma simples, mas envolve tensões e contradições, a identificação de uma situação que pode ser melhorada e a ação necessária para o alcance dessa mudança. Nesse sentido, o materialismo dialético emerge como importante meio de percepção da realidade, uma vez que esta, segundo a percepção materialista dialética, é transformada a partir das contradições e tensões existentes na própria realidade, sendo o processo social um processo dialético (MALAGODI, 1988).

Assim, o materialismo dialético é aqui acionado enquanto método de abordagem para o estudo do processo comunicacional de administrações públicas municipais, uma vez que este, na visão deste estudo, é considerado uma prática que envolve, não apenas os meios/canais, mas também os agentes - dotados de crenças e intuitos -, os fluxos informacionais, de diálogo, e o conteúdo compartilhado, buscando a equidade nas relações de poder entre emissor e receptor, bem como a simetria nos fluxos e na compreensão - a garantia de todos poderem ser, ao mesmo tempo, emissores e receptores, ouvir e ter voz, de compreender e serem compreendidos. Trata-se, portanto, de um processo dialético, possuidor de contradições, de tensões, assim como de forças transformadoras da realidade.

\section{O MATERIALISMO DiALÉtico E SUAS CONTRIBUIÇÕES PARA O ESTUDO DE PROCESSOS COMUNICACIONAIS}

O materialismo dialético é a base filosófica do marxismo, método de análise da sociedade que se inclui como uma tendência do materialismo filosófico e compreende três aspectos principais: o materialismo dialético, o materialismo histórico e a economia política. Várias ideias fundamentais para o marxismo tiveram como base as concepções de Hegel, como o conceito de alienação e seu ponto de vista dialético da compreensão da realidade. Contudo, ao invés de vincular tais ideias ao espírito absoluto hegeliano, Marx as desenvolve dentro de sua concepção materialista do mundo. Para o marxismo, a matéria é primordial, e a consciência, um produto da matéria, que permite o mundo nela reflita-se, o que assegura a possibilidade que o homem tem de conhecer o universo. Aideia materialista de mundo reconhece que a realidade existe independentemente da consciência (TRIVIÑOS, 1987). 
A dialética, em sua origem, nos tempos de Platão e Aristóteles, era entendida como a arte da discussão, à base de perguntas e respostas, e como técnica capaz de servir para classificar os conceitos e dividir os objetos em gêneros e espécies. Contudo, desde os tempos de Heráclito, começa- a se defender outra ideia básica em relação à dialética: a da mutabilidade do mundo e a da transformação de toda propriedade em seu contrário. A filosofia grega antiga ressaltou o aspecto contraditório do ser, que ao mesmo tempo que se transforma em outro, é único e múltiplo, imutável e passageiro (TRIVIÑOS, 1987). Assim, a dialética pode ser vista como "o movimento pelo qual as realidades sociais se desdobram e dão origem a novas realidades. [...] algo inerente ao movimento da história, à vida de qualquer sociedade", e, enquanto concepção metodológica, pode ser considerada o método que permite a captação desse movimento, "não apenas no estudo do passado mas do próprio presente” (MALAGODI, 1988, p. 64).

O materialismo dialético tenta buscar explicações coerentes, lógicas e racionais para os fenômenos da natureza, da sociedade e do pensamento. Por um lado, possui uma longa tradição na filosofia materialista e, por outro, baseia-se numa interpretação dialética do mundo. A dialética materialista reconhece como essência do mundo a matéria, em constante movimento, opondo-se às concepções idealistas, que admitem como substância de todos os fenômenos a "vontade divina", o "espírito", a "energia", etc., significando, neste sentido, uma superação do materialismo pré-marxista, no que este tem de metafísico e idealista. O materialismo dialético rejeita a ideia de que o homem não possui capacidade de conhecer o mundo, tendo ciência de que o conhecimento é relativo em determinada época histórica e que o homem é capaz de apreender a verdade absoluta , algo não imediato, mas gradual, no qual "o pensamento avança no conhecimento do objeto" (TRIVIÑOS, 1987, p. 25).

Para o materialismo dialético, tanto o indivíduo quanto as próprias coisas existem na natureza e na história, e se apresentam enquanto sujeito de um processo, ao longo do qual, desenvolvem-se a espécie humana, as sociedades, as classes, etc. Sua principal busca está na "verdade universal", possível pelo fato de o materialismo dialético escapar do vício comum de ver a sociedade a partir de um ponto de vista particular, seja de um indivíduo ou de uma classe. O caráter universal do materialismo dialético decorre do esforço de compreensão do conjunto do movimento, da totalidade da vida das sociedades, ou seja, "o passado, o presente e suas tendências para o 
futuro" (MALAGODI, 1988, p. 20-21). Assim, o passado contribui para a compreensão do presente e, consequentemente, para a formação de uma visão de futuro e possível transformação da sociedade através da ação, da prática.

O critério da verdade sustentado pelo materialismo dialético é a prática social, afirmando que a prática é o critério determinante para identificar a veracidade de um conhecimento e que a mesma está na base e no propósito final de todo do mesmo - o processo de conhecimento da realidade social implica na transformação da própria sociedade, mas para transformar a realidade é preciso conhecê-la, logo, estudá-la. O materialismo dialético entende o critério da prática em sentido amplo e variado, sendo considerada toda atividade material orientada para transformar a natureza e a vida social. A prática individual e a prática social estão profundamente relacionadas, pois a prática individual só pode se realizar e desenvolver com êxito, se estiver fundamentada na prática histórica e social acumulada pela humanidade, assim como a prática social se desenvolve e se enriquece através da atividade prática e teórica dos diferentes indivíduos e coletividades (MALAGODI, 1988; TRIVIÑOS, 1987).

A prática social, juntamente com a matéria e a consciência, são as categorias fundamentais do materialismo dialético, e os conceitos de conexão, interdependência e interação são essenciais no processo dialético de compreensão do mundo. O materialismo dialético tem como categoria essencial a contradição e como lei fundamental a Unidade e a Luta dos Contrários, pois reconhece que a contradição é uma forma universal do ser. A contradição é uma interação entre aspectos opostos e a origem do movimento e do desenvolvimento. Os contrários se excluem e estão, ao mesmo tempo, unidos. Sua luta leva à solução da contradição e à passagem da coisa de um estado qualitativo a um outro. Além da Lei da Unidade e da Luta dos Contrários, a dialética também possui as leis da Transformação da Quantidade em Qualidade e da Negação da Negação (TRIVIÑOS, 1987).

Objetos, coisas e fenômenos se distinguem por sua qualidade, pelo conjunto de propriedades que o caracteriza - estrutura, função, finalidade. Além da qualidade, há a quantidade, que caracteriza o objeto conforme o grau de desenvolvimento ou de intensidade das suas propriedades - dimensão, peso, volume. A passagem das mudanças quantitativas para as qualitativas é uma lei geral do desenvolvimento do mundo material (TRIVIÑOS, 1987), não significando, todavia, que os dados quantitativos devem ser negligenciados, mas que eles devem ser utilizados no desencadeamento de 
análises qualitativas da realidade. O trabalho, segundo o método dialético, atenta para a materialidade em movimento, revelando inúmeras contradições, sendo a negação dialética resultado da luta dos contrários. É através da negação da negação que se busca o conhecimento, sem contentamentos ou conclusões precipitadas - um conhecimento, ao ser negado, gera outro, mais profundo, que é negado novamente, gerando outro conhecimento ainda mais profundo, e assim sucessivamente (SALVADOR, 2012). Contudo, o novo não elimina o velho totalmente, pois possui muitos elementos do antigo, considerados positivos e que continuam existindo nele (TRIVIÑOS, 1987).

Desenvolver uma pesquisa segundo o materialismo dialético significa ter presente uma concepção dialética da realidade natural e social e do pensamento, bem como da materialidade dos fenômenos e de que são possíveis de se conhecer (TRIVIÑOS, 1987). O materialista dialético investiga o que existe de fato, não o que deseja que exista ou pensa existir; não faz constatações, mas compreende que o processo social é dialético, uma vez que a realidade se transforma a partir das forças das contradições e tensões internas dessa realidade. Tendo uma atitude de busca de conhecimento e sendo um ser ativo, o materialista dialético deve "agir-com-conhecimento" e "conhecer-com-a-ação", pois conhecimento e transformação do mundo são dois momentos de uma única síntese - não há como realizar plenamente um sem realizar simultaneamente o outro. A percepção que o materialista dialético possui da realidade revela uma carência - algo que falta - e uma riqueza não posta - algo que está por vir - e, uma vez que vive no interior da sociedade, o resultado do esforço de conhecimento da vida e do mundo se apresenta enquanto um programa de mudanças das condições em que se vive e de toda a sociedade (MALAGODI, 1988).

Pensar o processo comunicacional das administrações públicas municipais tendo em vista os preceitos de cidadania, democracia, empoderamento cidadão e desenvolvimento endógeno pode ser considerado "algo que falta”, mas que "está por vir”. É uma realidade de difícil alcance, devido às várias mudanças sociais necessárias para a sua viabilização, mas nem por isso deve ser vista como um idealismo inalcançável. Expor estas questões e trazê-las para o debate, de forma a analisar suas capacidades e limitações criticamente, é uma forma de demonstrar a possibilidade de materialidade dessa prática social e, uma vez sendo esta uma busca de conhecimento, também é uma forma de transformação. 
A ciência, na perspectiva dialética, se alicerça na noção de historicidade, na transformação da realidade, que é analisada de modo crítico. Os trabalhos científicos se dedicam à interpretação da totalidade em movimento, chegando à essência do concreto, às contradições, às desigualdades e às possibilidades de mudança, tendo em mente que tudo está em constante movimento, que a história é construída em um movimento em espiral - se repete, mas nunca do mesmo modo - e que o material produzido historicamente influencia as ações humanas atuais. A prática social é considerada categoria fundamental no trabalho com o método dialético, sendo a atenção dada à essência - qualitativo - e não à aparência - quantitativo (SALVADOR, 2012).

Portanto, analisar como se constitui o processo comunicacional de administrações públicas municipais sob o foco do materialismo dialético apresenta-se como importante, pois irá atentar para mais do que somente a aparência do processo, irá envolver a sua essência, o seu contexto, os conflitos existentes na comunicação e na implantação do processo comunicacional, tendo em vista o direito à informação e sua essencialidade para o exercício da cidadania, por sua vez considerada indutora de um desenvolvimento voltado para a região, para as pessoas, a partir de uma visão crítica da totalidade do processo, permitindo, assim, identificar seus benefícios e falhas e buscar sua superação.

\section{O PROCESSO COMUNICACIONAL NA MATERIALIDADE DAS ADMI- NISTRAÇÕES PÚBLICAS MUNICIPAIS}

Ao analisar o processo comunicacional das administrações públicas de três municípios pertencentes à região do Conselho Regional de Desenvolvimento (COREDE) do Vale do Rio Pardo (RS), identificados por Encruzilhada do Sul, Santa Cruz do Sul e Vera Cruz', tendo como marco teórico-metodológico o materialismo dialético, foi possível perceber que, embora o intuito dos processos seja muito semelhante - voltado para a informação dos cida-

\footnotetext{
1 Os dados aqui trazidos são oriundos dos resultados obtidos com o estudo realizado para a dissertação de mestrado da autora, intitulada "Comunicação, cidadania e administração pública municipal: um estudo a partir da política de acesso à informação em municípios da região do Vale do Rio Pardo (RS)", apresentada ao Programa de Pós-Graduação em Desenvolvimento Regional - área de concentração em Desenvolvimento Regional, linha de pesquisa em Território, Planejamento e Sustentabilidade - da Universidade de Santa Cruz do Sul (UNISC), sob orientação da Profa. Dra. Grazielle Betina Brandt.
} 
dãos -, o modo como o mesmo ocorre, na prática, se mostra distinto, sendo possível identificar um processo comunicacional mais informativo, outro mais consultivo e até mesmo um processo comunicacional que estimula práticas de corresponsabilidade. Esta dialética - intenção/ação -, bem como a materialidade do processo e a visualização das possibilidades de ação que, a partir disso, podem ser geradas, foram possíveis de serem identificadas a partir da realização de entrevistas semiestruturadas e de análise do conteúdo disponibilizado nos portais institucionais das administrações públicas municipais, a partir de uma pesquisa qualitativa.

As entrevistas, realizadas entre os dias 11 e 18 de setembro de 2017, tiveram como entrevistados os profissionais responsáveis pelo processo comunicacional das administrações públicas municipais, a saber: o Secretário Municipal de Comunicação da Prefeitura Municipal de Santa Cruz do Sul, Régis de Oliveira Júnior; a Dirigente do Núcleo de Comunicação Social da Prefeitura Municipal de Vera Cruz, Josileri Linke Cidade; e os servidores públicos do Departamento de Comunicação da Prefeitura Municipal de Encruzilhada do Sul, Antonio Valpir da Rocha (gestor), Nei Carvalho e Cristine da Silva Machado. O conteúdo disponibilizado nos portais institucionais dos municípios selecionados foi analisado/coletado na primeira quinzena do mês de novembro de 2017, através da técnica de análise de conteúdo, se valendo de indicadores não frequenciais, a saber: ausência ou presença - total ou parcial - dos itens analisados. Fez parte dessa análise o conteúdo disponibilizado pelas administrações públicas em cumprimento às exigências mínimas previstas na Lei de Acesso à Informação (LAI), assim como os conteúdos trazidos pelas últimas três notícias divulgadas, pela seção "Fale Conosco"|"Contato" - inclui-se o e-SIC e informações sobre o SIC físico - e pela seção específica dedicada à LAI. Também, foram considerados os documentos referentes à regulamentação da LAI nos municípios. Ainda, buscou-se identificar as características das informações disponibilizadas , a saber: facilidade de acesso, facilidade de compreensão, intuito, abrangência e produção. Por fim, buscou-se identificar o nível em que se encontrava o processo comunicacional das administrações públicas municipais, a partir do "Modelo de comunicação para a construção de consensos" apresentado por López et al. (2004) - Figura 1.

Figura 1: Modelo de comunicação para a construção de consensos 


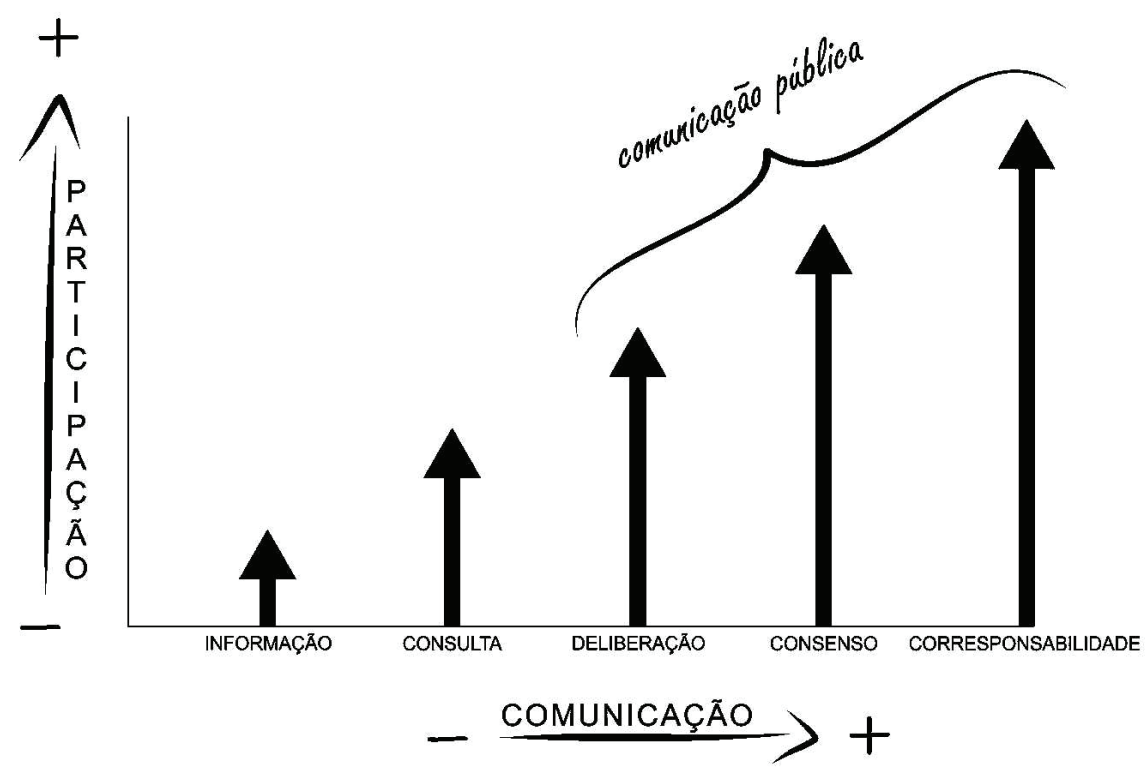

Fonte: Elaborado pela autora a partir de López et al. (2004).

Quanto aos setores de comunicação das administrações públicas, no município de Encruzilhada do Sul há o Departamento de Comunicação, contendo três servidores públicos, cada um responsável por uma área distinta - criação, redação, radialismo/gestão. No município de Santa Cruz do Sul há a Secretaria Municipal de Comunicação, contendo nove servidores públicos e núcleos internos - jornalismo, publicidade. No município de Vera Cruz há o Núcleo de Comunicação Social, contendo apenas uma servidora pública. Todos os setores estão vinculados diretamente ao Gabinete do Prefeito, demonstrando a proximidade que os mesmos possuem com a gestão da administração pública municipal . Cabe destacar que, nos municípios de Encruzilhada do Sul e Santa Cruz do Sul, os profissionais responsáveis participaram da campanha eleitoral dos respectivos prefeitos municipais, bem como todos os entrevistados estão em seus cargos a convite dos atuais prefeitos - são cargos de confiança (CCs) -, o que pode vir a influenciar, mesmo que indiretamente, suas formas de comunicar.

Quanto à função dos setores, todos estão voltados para atender às demandas provindas da administração pública - secretarias, departamentos, etc. -, estando a Secretaria de Comunicação do município de Santa Cruz do Sul também extremamente envolvida com a agenda do Prefeito. A divulgação de informações aos cidadãos também é um ponto em comum do processo comunicacional dos três municípios, sendo utilizados, para tanto, diversos meios de comunicação, algo que é trazido pela LAI, ao mencionar, 
além da obrigatoriedade de divulgação em meio digital, através dos portais institucionais dos órgãos públicos, a utilização de todos os meios e instrumentos legítimos de que dispuserem. Esse intuito de divulgar informações públicas aos cidadãos vai ao encontro das diretrizes da LAl, de observância da publicidade como preceito geral, de divulgação de informações de interesse público independentemente de solicitação, assim como o fomento ao desenvolvimento de uma cultura de transparência e do controle social na administração pública (BRASIL, 2011).

No estudo, foi possível perceber que, nos três municípios selecionados, a utilização de meios que possibilitam tanto a divulgação de informações quanto o diálogo entre administração pública e cidadãos, e os profissionais responsáveis acreditam que esta divulgação incentiva a população a participar, assim como acreditam que disponibilizam os canais para que esta participação aconteça. Aqui, é possível perceber uma abordagem, de certa forma, tecnicista por parte dos entrevistados, voltado para a ideia de que se possuem os meios, a participação pode ser realizada. A existência de meios que possibilitem a participação da sociedade é importante, contudo, considerando a perspectiva de Duarte (2007), a simples existência de instrumentos não significa a sua apropriação pelos interessados, o que demanda conhecimento, acesso e compreensão, por parte dos cidadãos. Além disso, durante as entrevistas/análise de conteúdo muito do que se visualizou foram situações de consulta, repasse de informações. A participação em nível de ação foi visualizada apenas no município de Vera Cruz, onde foi possível perceber uma certa tensão, uma contradição entre discurso e prática, pois há a consciência da importância da divulgação de informações e da participação dos cidadãos na administração pública, bem como da realização de tais atividades, mas, na prática, isto nem sempre é visualizado.

Quanto aos portais institucionais municipais, no pertencente ao município de Encruzilhada do Sul foi percebido que as informações, em muitos casos, eram parciais, até mesmo ausentes. Para localizar determinadas informações, foi preciso percorrer diversas páginas, mas as informações disponíveis possuíam fácil compreensão, à exceção das informações do Portal da Transparência. No portal institucional da Prefeitura Municipal de Santa Cruz do Sul, foi percebido que as informações públicas estavam, em sua maioria, completas e eram de fácil compreensão e localização, à exceção de alguns dados financeiros. Todos os itens de análise foram encontrados , embora alguns pontos importantes apresentassem informações parciais, como 
referentes à LAI e ao SIC. Já o portal institucional da Prefeitura Municipal de Vera Cruz passou por um processo licitatório no final de 2017, sofrendo alterações estéticas e estruturais. Na análise, foi percebido que as informações públicas estavam, em sua maioria, completas e disponíveis, embora em páginas importantes, como sobre a LAI e e-SIC, estivessem ausentes. As informações visualizadas eram de fácil compreensão e localização, exceto em buscas e no Portal da Transparência.

Quanto às características das informações públicas disponibilizadas, os portais institucionais dos três municípios apresentavam informações que diziam respeito ao município, a exceção de determinadas informações do Portal da Transparência, que se apresentam enquanto um padrão de todos os Portais. Este saber local, esta informação produzida no território é apresentada por Santos e Silveira (2006) como uma possibilidade de dinamizar a economia pela base, contribuindo para uma redução da dependência e da desigualdade entre locais. Tais informações públicas possuíam, em grande parte, um intuito informativo - alguns casos também educativo -, não demonstrando nenhuma promoção pessoal, política ou partidária de forma explícita, embora fosse possível identificar, em alguns conteúdos - também algumas falas das entrevistas -, características de uma comunicação governamental, até mesmo política, voltada para os governantes e seus feitos. Não se trata de propaganda explícita, mas de informar o que está sendo feito, o que pode levar a interpretações distintas, como apenas informação ou como uma publicidade velada - e eis aqui um outro ponto de tensão, ao se comparar com o intuito mencionado nas entrevistas de um processo comunicacional voltado para a população. Quanto à produção, por mais que algumas informações públicas estivessem presentes em páginas externas aos portais institucionais, as mesmas provinham de dados repassados pelo município - à exceção da legislação municipal, que tem como base os preceitos de uma construção exógena.

Tendo em vista estas questões, e levando em consideração o "Modelo de comunicação para a construção de consensos" apresentado por López et al. (2004), foi possível identificar o processo comunicacional das administrações públicas municipais em distintos níveis. O processo comunicacional referente ao município de Encruzilhada do Sul foi identificado no nível primário, da informação², pois, por mais que exista um diálogo entre admi- 
nistração pública e cidadãos, não foi identificada a realização deste a nível de consulta ${ }^{3}$ - o diálogo se dá na busca de informações pelos cidadãos e resposta por parte da administração pública. O processo comunicacional da administração pública do município de Santa Cruz do Sul, por sua vez, foi identificado no nível secundário, da consulta. Apesar de considerar as demandas trazidas pelos cidadãos em seu processo comunicacional, não foi identificada uma participação a nível de deliberação ${ }^{4}$. Já o processo comunicacional realizado pela administração pública do município de Vera Cruz foi identificado no nível máximo, da corresponsabilidade ${ }^{5}$. Muito do seu processo comunicacional possui relação com o nível secundário, da consulta, contudo, quando a população é chamada a participar das ações da administração pública municipal, ela se mobiliza, exercendo sua cidadania em um processo de gestão participada.

\section{CONSIDERAÇÕES FINAIS}

Com a utilização do materialismo dialético enquanto método de abordagem do estudo, foi possível perceber não apenas o modo como se dá o processo comunicacional das administrações públicas dos municípios selecionados, mas, também, a importância da comunicação para o estabelecimento de uma cultura de transparência na administração pública, através da divulgação de informações públicas aos seus cidadãos, seja em cumprimento do disposto na LAI ou por considerar importante disponibilizar esse conhecimento para a sociedade. Também, foi visualizado o quanto a comunicação pode contribuir para o estabelecimento de um diálogo entre cidadãos e administração pública, bem como para o empoderamento e mobilização da população, incentivando a sua participação em temas caros ao município.

Ter espaços para adquirir conhecimento e ter poder de expressão é fun-

do seu instrumento básico a notícia (LÓPEZ et al., 2004).

3 Capacidade de consultar e disponibilidade de ser consultado através de instrumentos como entrevista, pesquisa, grupos focais, mesas de trabalho consultivas ou pesquisas de opinião (LÓPEZ et al., 2004).

4 Capacidade de deliberar e disposição para reconhecer os argumentos do outro em cenários como fóruns, palestras ou painéis, debate público ou discussão em grupo (LÓPEZ et al., 2004).

5 Capacidade de assumir compromissos de forma corresponsável, mediante a gestão conjunta ou participada (LÓPEZ et al., 2004). 
damental para o estabelecimento de uma comunicação voltada para a cidadania, uma comunicação para o desenvolvimento, sendo este visto em sintonia com o conceito de Sen (2000), que envolve a qualidade de vida da sociedade, possível através da eliminação das privações de suas liberdades. Liberdades como garantia de transparência, oportunidades sociais e liberdades políticas (SEN, 2000) estão extremamente relacionadas aos processos comunicacionais voltados para a cidadania, uma vez que a divulgação de informações públicas e garantia ao seu acesso - preceitos da LAI - podem garantir a transparência de órgãos públicos, bem como a capacitação dos cidadãos para a participação e fiscalização de seus representantes. Estas práticas, por sua vez, tratam-se de liberdades políticas, que contribuem - assim como dependem - para as oportunidades sociais.

Portanto, a busca por um outro desenvolvimento passa pela garantia das liberdades dos cidadãos, pela sua auto-emancipação e seu empoderamento. No meio técnico-científico-informacional, a informação se apresenta enquanto um fator extremamente importante na forma como os territórios são constituídos e utilizados, definindo, junto com outros fatores-chave, uma hierarquia territorial, gerando desigualdades e dependências. $E$, uma vez que é no território que se dá a ação da sociedade, a informação também se apresenta como importante para este processo (SANTOS, SILVEIRA, 2006; SANTOS, 2004). A comunicação, ao envolver tanto informação quanto diálogo e participação, torna-se um fator importante ao pensar a mobilização das técnicas atuais em busca de outros fundamentos sociais e políticos, na busca de um outro desenvolvimento (SANTOS, 2000).

A esfera municipal é a esfera pública mais próxima dos cidadãos, seu local de moradia e de ação, logo, a base para um desenvolvimento construído de forma endógena. Nos casos aqui estudados, percebeu-se que as bases para o empoderamento e mobilização dos cidadãos estão presentes nos processos comunicacionais, embora nem sempre sejam acionadas . Como se trata de um processo, esta relação não está dada nem está pronta, há que ser trabalhada, melhor analisada e explorada, afinal, o conhecimento é a base da ação. A comunicação é uma das técnicas que podem ser empregadas para tanto, mas a mudança está nas pessoas. No município de Vera Cruz, a mobilização e organização da sociedade em parceria com a administração pública municipal pode ser identificada, tendo a comunicação um importante papel. Os demais municípios de estudo também possuem esta base, cabendo aos envolvidos se valerem da mesma para seu empodera- 
mento.

Pensar o desenvolvimento regional de forma endógena passa pelo exercício da cidadania e da democracia, pela luta por direitos, e isso, por sua vez, passa pela obtenção de conhecimento - através da informação - e pelo diálogo. Utilizar a comunicação para outros fins, sociais, políticos, é necessário, não apenas para a realização do ideal de um desenvolvimento endógeno, mas para superar as desigualdades, as crueldades, as indiferenças e as injustiças. Trata-se da conquista de uma sociedade cidadã, democrática e equitativa, possível através da articulação dos agentes envolvidos no processo de desenvolvimento - administração pública e cidadãos. Nesta construção, a comunicação se faz presente como uma - não a única - ferramenta, tendo em vista que permite a obtenção de conhecimento e a organização para a ação. São os cidadãos, através de suas ações, que podem transformar a realidade. A necessidade está posta, e as alternativas para a superação da atual condição estão no conhecimento e na ação, na luta. Neste período do século XXI, carregado de perversidades, isso soa como utopia, mas já diria Milton Santos (2000), o mundo não é formado apenas pelo que já existe, mas pelo que pode vir a existir, e situações como a de agora podem parecer definitivas, mas não são verdades eternas.

\section{REFERÊNCIAS}

BANDEIRA, P. S. Participação, articulação de atores sociais e desenvolvimento regional. In: BECKER, D. F.; BANDEIRA, P. S. (Org.). Determinantes e desafios contemporâneos. Santa Cruz do Sul: EDUNISC, 2000. p. 23-128.

BRASIL. Lei $n^{\circ} 12.527$, de 18 de novembro de 2011. Regula o acesso a informações previsto no inciso XXXIII do Art. $5^{\circ}$, no inciso II do $\S 3^{\circ}$ do Art. 37 e no $\S 2^{\circ}$ do Art. 216 da Constituição Federal; altera a Lei no 8.112, de 11 de dezembro de 1990; revoga a Lei $n^{\circ} 11.111$, de 5 de maio de 2005, e dispositivos da Lei n 8.159, de 8 de janeiro de 1991; e dá outras providências. Diário Oficial [da] República Federativa do Brasil, Brasília, DF, 18 nov. 2011. Disponível em: <http://www.planalto.gov.br/ ccivil_03/_ato2011-2014/2011/lei/l12527.htm>. Acesso em: 28 jul. 2017.

DUARTE, J. Instrumentos de comunicação pública. In: (Org.). Comunicação pública: estado, mercado, sociedade e interesse público. São Paulo: Atlas, 2007. p. 59-71.

FOSSATTI, N. C. Gestão da comunicação na esfera pública municipal. Porto Alegre: Sulina, 2006.

JENATSCH, T.; BAUER, R. Communication for Development: a practical guide. Bern, Switzerland: Swiss Agency for Development and Cooperation (SDC), 2016. Disponível em: <https://www.eda.admin.ch/dam/deza/en/documents/publikationen/Diverses/ Communication-for-development-Manual_EN.pdf>. Acesso em: 6 dez. 2017. 
LÓPEZ, J. C. J. et al. Modelo de comunicación pública organizacional e informativa para entidades del Estado (MCPOI). Bogotá: Usaid/Casals \& Associates Inc., 2004.

MALAGODI, E. O que é materialismo dialético. 2.ed. São Paulo: Brasiliense, 1988.

SALVADOR, D. S. C. O. A geografia e o método dialético. Sociedade e Território, Natal, v. 24, n. 1, jan.-jun. 2012. p. 97-114. Disponível em: <https://periodicos.ufrn.br/ sociedadeeterritorio/article/view/3466/2779>. Acesso em: 7 nov. 2017.

SANT’ANA, R. C. G. Tecnologia e gestão pública municipal: mensuração da interação com a sociedade. São Paulo: Cultura Acadêmica, 2009.

SANTOS, M. Técnica, espaço, tempo: globalização e meio técnico-científico informacional. 3. ed. São Paulo: HUCITEC, 1997.

. Por uma outra globalização: do pensamento único à consciência universal. Rio de Janeiro: Record, 2000.

. Por uma geografia nova: da crítica da geografia a uma geografia crítica. 6. ed. São Paulo: Editora da Universidade de São Paulo, 2004.

. A natureza do espaço: técnica e tempo, razão e emoção. 4. ed. 2. reimpr. São Paulo: Editora da Universidade de São Paulo, 2006.

; SILVEIRA, M. L. O Brasil: território e sociedade no início do século XXI. 9. ed. Rio de Janeiro: Record, 2006.

SEN, A. K. Desenvolvimento como liberdade. São Paulo: Companhia das Letras, 2000.

SERVAES, J. Comunicación para el desarrollo: tres paradigmas, dos modelos. Temas y Problemas de Comunicacion, Río Cuarto, ano 8, v. 10, p. 5-27, 2000. Disponível em: <http://catedras.fsoc.uba.ar/gpost/material/servaes.pdf>. Acesso em: 10 abr. 2017.

SILVA, L. M. Comunicação e cidadania - conceitos básicos. In: FORMIGA SOBRINHO, A. B. et al. Comunicação e cidadania: conceitos e processos. Brasília, DF: Francis, 2011. p. 95-113.

TRIVIÑOS, A. N. S. Introdução à pesquisa em ciências sociais: a pesquisa qualitativa em educação. 1. ed. São Paulo: Atlas, 1987. 


\section{Tamara Arend de Freitas}

Mestra em Desenvolvimento Regional pela Universidade de Santa Cruz do Sul (UNISC). Graduada em Comunicação Social - Habilitação Relações Públicas pela Universidade de Santa Cruz do Sul (UNISC).

E-mail: tamaraarendf@gmail.com

\section{Grazielle Betina Brandt}

Doutora em Desenvolvimento Regional pela Université du Quebéc à Rimouski - UQAR. Docente e pesquisadora do Departamento de Comunicação Social e do Programa de Pós-graduação em Desenvolvimento Regional da Universidade de Santa Cruz do Sul (UNISC).

E-mail: grazielle@unisc.br 